\title{
CORRELATIONS OF THE MEAN TIME AND MEAN MAGNITUDE OF ACCELERATING PRESHOCKS WITH THE ORIGIN TIME AND MAGNITUDE OF MAINSHOCK
}

\author{
Scordilis E. M. \\ Department of Geophysics, School of Geology, Faculty of Science, Aristotle University, GR54124, \\ Thessaloniki,GREECE,manolis@geo.auth.gr
}

\begin{abstract}
Forty-five preshock sequences preceding corresponding strong $(M \geq 6.4)$ mainshocks which occurred recently (since 1980) in a variety of seismotectonic regimes (W. Mediterranean, Aegean, Anatolia, California, Japan, Central Asia, South America) have been examined to identify new predictive properties. It has been observed that the mean origin time, , and the mean magnitude,

of the accelerating preshocks of each sequence are correlated with the origin time, $t_{c}$, and the magnitude, $M$, of the mainshock, respectively. The following relations have been derived:
\end{abstract}

where $s_{a}\left(\right.$ in Joule ${ }^{1 / 2} / y r .10^{4} \mathrm{Km}^{2}$ ) is the Benioff strain rate in each preshock (critical) region and $\sigma$ is the corresponding standard deviation. The possibility for using these relations as constraints in attempts for intermediate term earthquake prediction is discussed.

Keywords: Accelerating strain, accelerating preshocks, critical earthquake, intermediate-term earthquake prediction.

\section{Introduction}

Shocks which are considered as related genetically to an ensuing strong mainshock are foreshocks and preshocks. Foreshocks are generated in the mainshock fault region within a short time (days to weeks) before the mainshock. Foreshocks, however, are usually small and almost unidentifiable before the generation of the mainshock. Preshocks occur years before a strong $(\mathrm{M}>6.0)$ mainshock in a relatively broad region and their magnitudes are relatively large $(\mathrm{M}>4.0)$. Properties of preshocks are known before the generation of the mainshock and for this reason knowledge of their space, time and magnitude distribution is of significance for intermediate-term prediction of strong mainshocks.

Preshocks can be separated in two categories. The first category includes preshocks which release accelerating seismic strain energy (accelerating preshocks) and their foci are located in a relatively broad region (critical region). The second category includes smaller preshocks which release decelerating seismic strain energy (decelerating preshocks) and their foci are located in a narrower region (seismogenic region). 
Accelerating preshocks have been observed by many seismologists (Tocher, 1959; Varnes, 1989; Sykes and Jaumé, 1990; Knopoff et al., 1996; Brehm and Braile, 1999; Tzanis et al., 2000; Ben-Zion and Lyakhovsky, 2002; Karakaisis et al., 2003; Scordilis et al., 2004; Papazachos et al., 2005) and interpreted in terms of the critical point dynamics (Sornette and Sammis, 1995; Rundle et al., 2003). Bufe and Varnes (1993) proposed the following relation for the time variation of accelerating preshocks:

where $\mathrm{S}(\mathrm{t})$ is the cumulative Benioff strain (square root of seismic energy) released by accelerating preshocks, $t$ is the time to the mainshock, $t_{c}$ is the origin time of the mainshock and $A$, $\mathrm{B}$ and $\mathrm{m}$ are constants with $\mathrm{m}<1$. Bowman et al. (1998) proposed a curvature parameter, C, which is defined as the ratio of the root-mean-square error of the power-law fit (relation 1) to the corresponding linear fit error, to quantify the deviation of the time variation of the Benioff strain from linearity.

Decelerating preshocks have been also observed before many strong mainshocks and their time variation is also expressed by a relation of the form (1) with $m>1$ (Papazachos et al., 2005, 2006a). The decelerating seismic strain is attributed to static stress shadow (Papazachos et al., 2006a) that can be interpreted by the Stress Accumulation Model (Bowman and King, 2001; King and Bowman, 2003).

Papazachos et al. (2006a), based on published information on decelerating and accelerating precursory seismic strain and on relative global data, developed the Decelerating-Accelerating Seismic Strain (D-AS) model. This model is formed of a series of empirical relations, most of which have been physically interpreted and can be used to estimate (predict) the origin time, epicenter coordinates and the magnitude of strong mainshocks. The $2 \sigma$ model uncertainties are $\delta x \leq 150 \mathrm{Km}$ for the epicenter, \pm 2.5 years for the origin time and \pm 0.4 for the magnitude of the ensuing mainshock. This model has been already used for a successful, scientifically valid prediction in 2002 of a large earthquake which occurred in southwestern Aegean on 8 January 2006 (Papazachos et al., 2006b, 2007).

In the present work, global data are used to define new properties of accelerating preshock sequences. These properties are expressed by empirical relations that can be used as additional constraints in the effort for intermediate term earthquake prediction. In particular, correlations are observed between the mean origin time, , and the mean magnitude, , of accelerating preshocks with the mainshock origin time, $\mathrm{t}_{\mathrm{c}}$, and magnitude, $\mathrm{M}$, respectively.

\section{The Data}

Data concerning preshock sequences of 45 strong $(M \geq 6.4)$ mainshocks, which occurred in a variety of seismotectonic regimes, are used in the present study. Of these mainshocks: three (3) occurred in Western Mediterranean (with $M \geq 6.8$ since 1980), nine (9) in Aegean $(M \geq 6.4$ since 1980), five (5) in Anatolia ( $M \geq 6.4$ since 1980), eight (8) in California ( $M \geq 6.4$ since 1980), eight (8) in Japan ( $M \geq 7.0$ since 1990), nine (9) in Central Asia ( $M \geq 7.0$ since 1990) and three (3) in South America ( $M \geq 7.7$ since 1995). The first four columns of table (1) list the region, origin time, $\mathrm{t}_{\mathrm{c}}$, epicenter coordinates, $\mathrm{E}(\phi, \lambda)$, and magnitude, $\mathrm{M}$, of all these forty five mainshocks.

Data concerning the accelerating preshocks of these forty five mainshocks needs to be accurate with respect to their epicenter location and magnitude, and homogeneous with respect to their 
Table 1. Region, origin time, tc, epicenter coordinates, $\mathrm{E}(\phi, \lambda)$ and magnitude, $\mathrm{M}$, of each mainshock are given in the first four columns for all 45 mainshocks. Q is the center and R (in km) is the radius of the preshock (critical) region, $\mathrm{t}_{\mathrm{sa}}$ is the start time of the accelerating preshock sequence, $\mathrm{M}_{\min }$ is the minimum preshock magnitude, $\mathrm{s}_{\mathrm{a}}$ (in Joule $1 / 2 / \mathrm{yr}^{1} 10^{4} \mathrm{~km}^{2}$ ) is the strain rate in the critical region, is the mean origin time and the mean magnitude of the accelerating preshocks which occurred between the origin time, $\mathrm{t}_{\mathrm{c}}$ and the time, $\mathrm{t}_{\mathrm{e}}$, when the maximum (best) value of the quality index is observed.

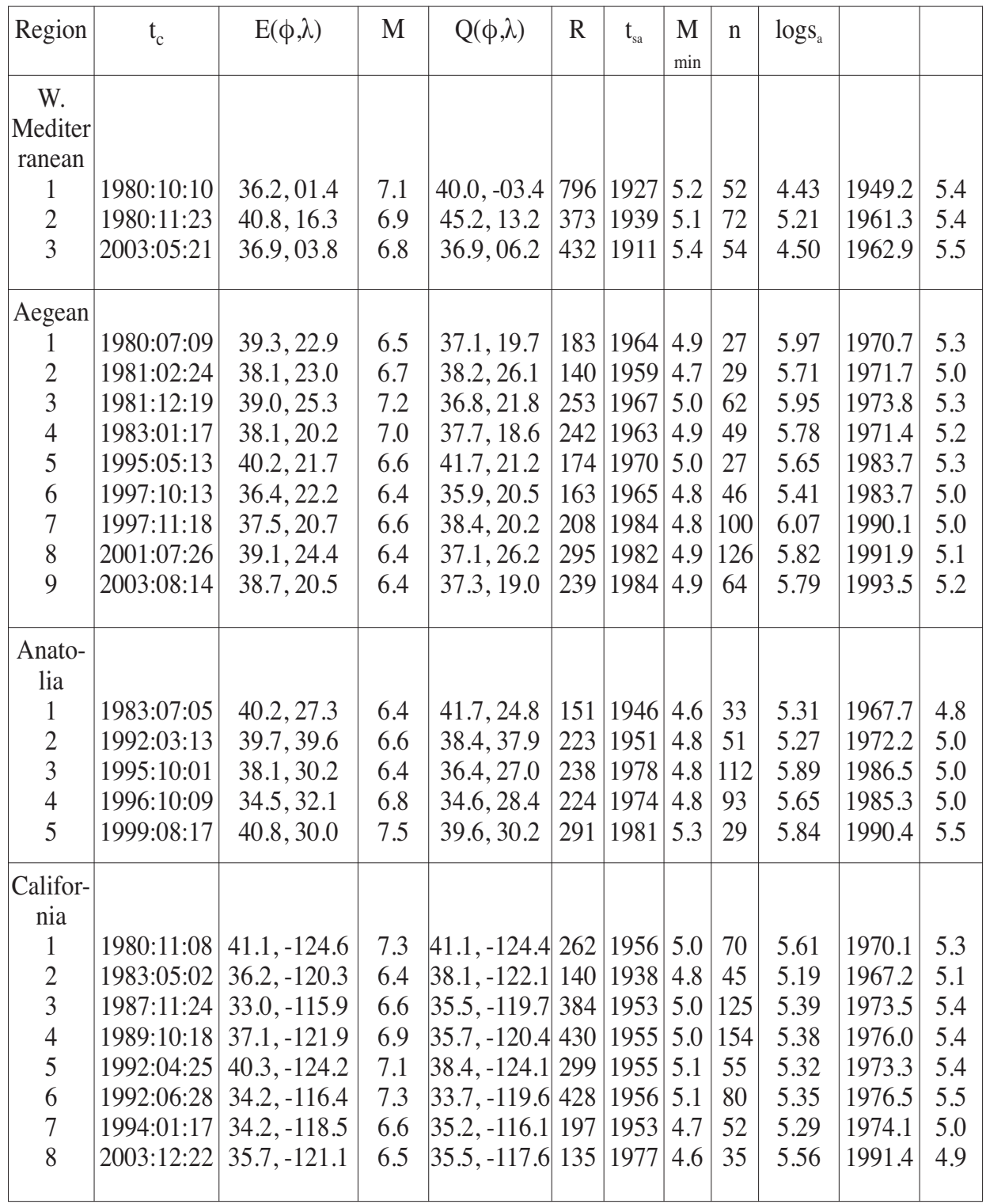




\begin{tabular}{|c|c|c|c|c|c|c|c|c|c|c|c|}
\hline Region & $t_{c}$ & $\mathrm{E}(\phi, \lambda)$ & $\mathrm{M}$ & $\mathrm{Q}(\phi, \lambda)$ & $\mathrm{R}$ & $t_{\mathrm{sa}}$ & $\begin{array}{c}\mathrm{M} \\
\min \end{array}$ & $\mathrm{n}$ & $\log _{\mathrm{a}}$ & & \\
\hline \multicolumn{12}{|l|}{ Japan } \\
\hline 1 & 1993:07:12 & $42.9,139.2$ & 7.7 & $38.7,136.3$ & 572 & 1969 & 5.5 & 141 & 6.04 & 1980.5 & 5.8 \\
\hline 2 & 1994:10:04 & $43.7,147.4$ & 8.3 & $41.5,148.0$ & 746 & 1982 & 5.6 & 135 & 6.08 & 1986.9 & 6.0 \\
\hline 3 & 1995:01:16 & $34.6,135.0$ & 7.0 & $34.3,137.3$ & 198 & 1983 & 5.0 & 65 & 6.17 & 1988.6 & 5.2 \\
\hline 4 & 2003:05:26 & $38.8,141.6$ & 7.0 & $38.5,139.3$ & 223 & 1985 & 5.1 & 54 & 5.86 & 1993.4 & 5.3 \\
\hline 5 & 2003:09:25 & $41.8,143.9$ & 8.3 & $41.8,143.4$ & 2503 & 1964 & 6.0 & 310 & 5.26 & 1983.9 & 6.3 \\
\hline 6 & 2003:10:11 & $37.8,142.6$ & 7.0 & $34.7,143.0$ & 165 & 1987 & 4.8 & 50 & 5.91 & 1994.5 & 5.1 \\
\hline 7 & 2004:09:05 & $33.2,137.1$ & 7.4 & $31.7,135.2$ & 443 & 1972 & 5.4 & 87 & 5.84 & 1989.2 & 5.7 \\
\hline 8 & 2005:08:16 & $38.3,142.0$ & 7.2 & $40.4,141.2$ & 172 & 1996 & 5.1 & 24 & 6.37 & 1999.4 & 5.4 \\
\hline \multicolumn{12}{|l|}{$\begin{array}{c}\text { Central } \\
\text { Asia }\end{array}$} \\
\hline 1 & 1990:06:20 & $37.0,49.1$ & 7.4 & $34.6,51.4$ & 798 & 1949 & 5.3 & 223 & 5.29 & 1972.5 & 5.6 \\
\hline 2 & 1992:08:19 & $42.1,73.6$ & 7.2 & $42.2,75.0$ & 306 & 1963 & 5.3 & 39 & 5.48 & 1977.5 & 5.5 \\
\hline 3 & 1997:02:27 & $30.0,68.2$ & 7.0 & $27.8,70.0$ & 510 & 1940 & 5.2 & 115 & 4.90 & 1976.1 & 5.5 \\
\hline 4 & 1997:05:10 & $33.9,59.8$ & 7.3 & $30.5,63.2$ & 622 & 1942 & 5.5 & 66 & 5.00 & 1980.7 & 5.9 \\
\hline 5 & 1997:11:08 & $35.1,87.4$ & 7.5 & $36.4,87.7$ & 690 & 1940 & 5.2 & 151 & 4.79 & 1983.0 & 5.5 \\
\hline 6 & 2000:12:06 & $39.6,54.8$ & 7.0 & $39.4,54.1$ & 488 & 1958 & 5.2 & 92 & 5.20 & 1981.1 & 5.4 \\
\hline 7 & 2001:01:26 & $23.4,70.2$ & 7.6 & $25.8,68.2$ & 701 & 1955 & 5.5 & 31 & 5.03 & 1981.6 & 5.8 \\
\hline 8 & 2001:11:14 & $35.9,90.5$ & 7.8 & $37.9,94.7$ & 654 & 1948 & 5.4 & 65 & 4.91 & 1982.5 & 5.7 \\
\hline 9 & 2005:10:08 & $34.5,73.6$ & 7.5 & $31.5,73.7$ & 586 & 1976 & 5.3 & 75 & 5.27 & 1988.6 & 5.6 \\
\hline \multicolumn{12}{|l|}{$\begin{array}{c}\text { South } \\
\text { Amer- } \\
\text { ica }\end{array}$} \\
\hline 1 & 1995:10:09 & $19.1,-104.2$ & 7.9 & $22.1,-103.2$ & 156 & 1966 & 5.6 & 166 & 5.04 & 1979.0 & 5.9 \\
\hline 2 & 2001:01:13 & $13.0,-88.7$ & 7.7 & $10.0,-87.2$ & 1020 & 1965 & 5.5 & 259 & 5.34 & 1983.3 & 5.8 \\
\hline 3 & 2001:06:23 & $-16.3,-73.6$ & 8.3 & $-18.8,-74.1$ & 1062 & 1965 & 5.6 & 196 & 5.33 & 1981.4 & 5.9 \\
\hline
\end{tabular}

magnitude scale. These data must also be complete, that is, to include all preshocks which occurred in certain region and certain time period and have magnitudes larger than a certain value. The epicenter locations have an error of less than $30 \mathrm{~km}$ which is satisfactory for the present work which concerns circular regions (critical regions) with radii of hundreds of kilometers. The error in magnitudes is less than 0.3 which is also satisfactory for the purpose of the present work. All magnitudes are in the moment magnitude scale or converted to this scale form other scales $\left(\mathrm{m}_{\mathrm{b}}, \mathrm{M}_{\mathrm{s}}, \mathrm{M}_{\mathrm{JMA}}\right)$ by appropriate formulae (Scordilis, 2005, 2006).

Complete data are needed for two purposes. The first purpose is to calculate the Benioff strain rate, $\mathrm{s}_{\mathrm{a}}$ (in Joule ${ }^{1 / 2} /$ year. $10^{4} \mathrm{Km}^{2}$ ), which is needed in the present work. Data of preshocks with $M \geq 5.2$ are used for this purpose. Such complete data (with $M \geq 5.2$ ) are available since 1911 for the whole Mediterranean (W. Mediterranean, Aegean, Anatolia), since 1930 for California, since 1926 for Japan, since 1940 for central Asia and since 1965 for South America. The second purpose for which complete data are needed is the calculation of the Benioff strain for the whole duration of each preshock sequence (from the start time, $t_{\mathrm{s}}$, of each sequence to the origin time, $t_{c}$, of the mainshock) in order to reliably calculate the average time, , and the average magnitude, , of each sequence. We checked very carefully all 45 sequences and found 

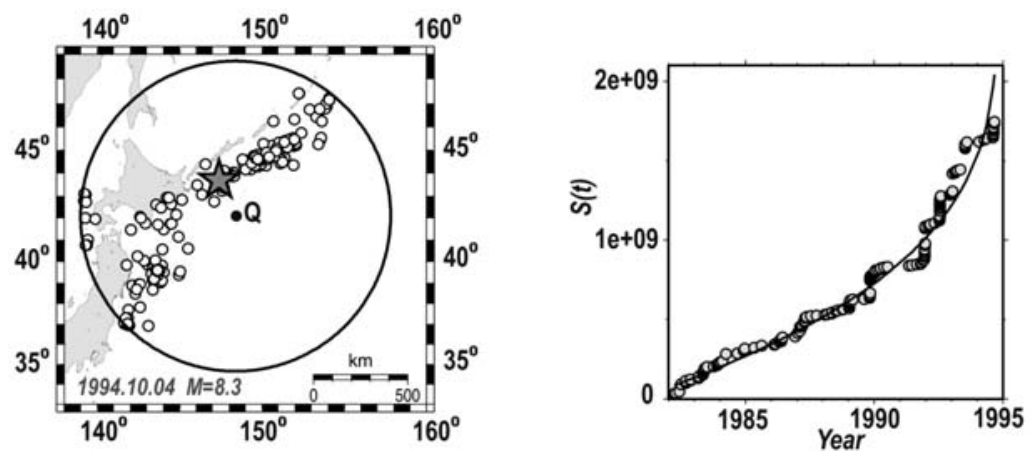

Fig. 1. The circular critical region where accelerating preshocks (open circles) occurred before the generation of the big $(\mathrm{M}=8.3)$ mainshock of October 4, 1994 in northern Japan $\left(43.7^{\circ} \mathrm{N}, 147.4^{\circ} \mathrm{E}\right)$. The star denotes the mainshock epicenter while $\mathrm{Q}$ is the center of the circular region (solid circle). On the right of the map, the time variation of the cumulative Benioff strain, $\mathrm{S}(\mathrm{t})$, for the accelerating preshocks is given. The solid line represents fitting to the data of a power-law (relation 1).

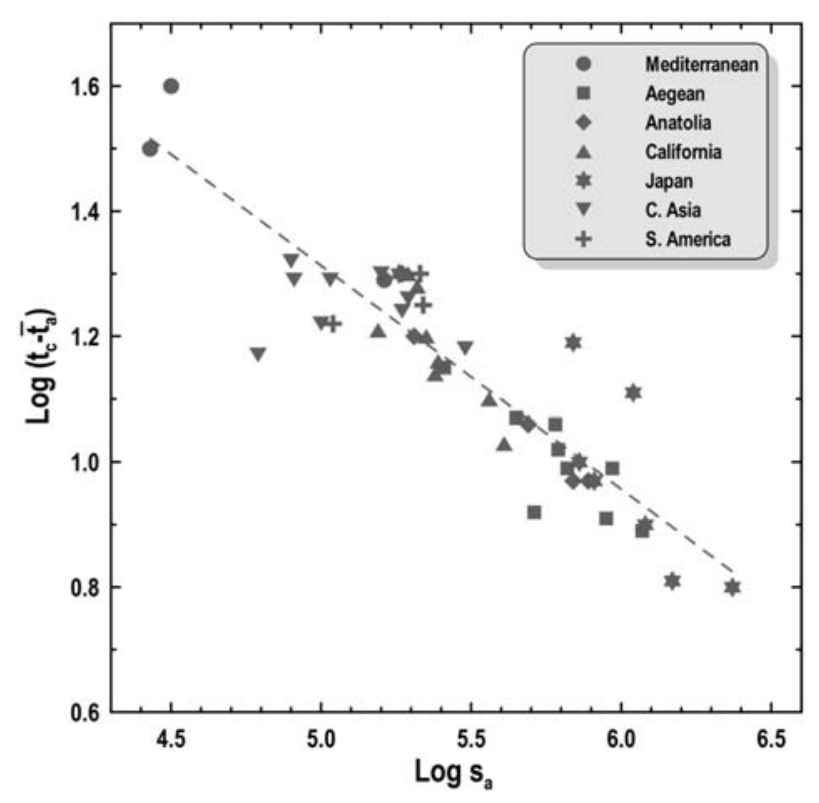

Fig. 2: Variation of the logarithm of the time difference between the origin time, $t_{c}$, of the mainshock and the mean origin time, , of accelerating preshocks with the logarithm of the Benioff strain rate, $\mathrm{s}_{\mathrm{a}}$, in the preshock (critical) region. The data are fitted by a straight line (dashed line) in the least-squares' sense.

that all sequences are complete for the corresponding periods between $t_{s}$ and $t_{c}$. Such catalogues, for each of the regions considered, have been already compiled for the needs of other studies where details on the procedure followed are given (Karakaisis et al., 2006; Papaioannou et al., 2006; Papazachos et al., 2006c; Scordilis et al., 2006;).

\section{Procedure Followed}

The circular regions where accelerating preshocks occurred have been identified and the start time, $\mathrm{t}_{\mathrm{s}}$, of each accelerating preshock sequence has been calculated in previous work (Papazachos et al., 2005, 2006a). The fifth and sixth column of Table (1) list the geographic coor- 


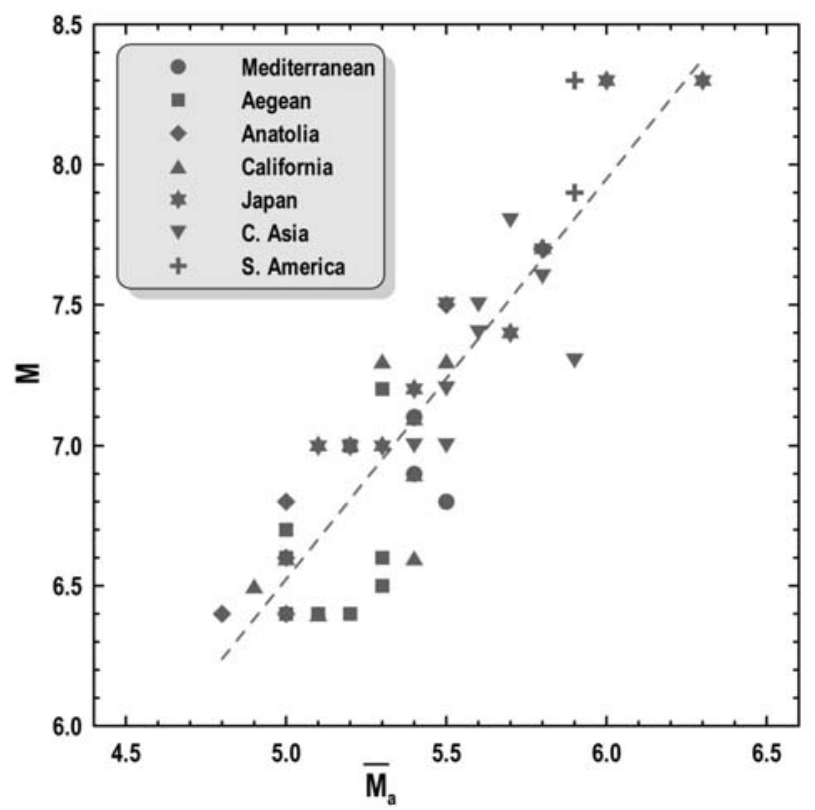

Fig. 3: Variation of the mainshock magnitude, $\mathrm{M}$, with the mean magnitude, , of accelerating preshocks. The data are fitted by a straight line (dashed line) in the least-squares' sense.

dinates of the center, $\mathrm{Q}$, and the radius, $\mathrm{R}$ (in $\mathrm{km}$ ), of each circular region (critical region) where the epicenters of accelerating preshocks are located. In the same table the start time, $\mathrm{t}_{\mathrm{sa}}$ (in years), the minimum preshock magnitude, $\mathrm{M}_{\min }$, and the number, $\mathrm{n}$, of accelerating preshocks are also listed. These listed values have been defined by constraints put by the D-AS model which was developed on the basis of observations and theoretical considerations (Papazachos et al. 2005, 2006a).

It has been shown (Papazachos et al., 2006b) that the cumulative Benioff strain is increasing with the time to the mainshock, according to the power law relation (1), up to a certain time, $t_{e}$, (about 3 years before the generation of the mainshock) and then it declines. This decrease of the Benioff strain during the last phase of the accelerating sequence is due to increase of the frequency and mean magnitude of preshocks. The left part of figure (1) shows the circular critical region, its center, Q, the epicenters of accelerating preshocks and the epicenter of the big mainshock $(\mathrm{M}=8.3)$ which occurred on 4.10.1994 in northern Japan. The right part of this figure shows the time variation of the cumulative Benioff strain for these preshocks.

The time, $\mathrm{t}_{\mathrm{e}}$, when this decrease starts is accurately determined by a plot of a quality index, $\mathrm{q}_{\mathrm{a}}$, as a function of the time to the mainshock, while the time when this index gets its largest value is the time, $\mathrm{t}_{\mathrm{a}}$, when declination starts (Papazachos et al., 2006b).

For this reason, preshocks which occurred between the start time, $\mathrm{t}_{\mathrm{s}}$, of each sequence and the time, $t_{e}$, when the decrease of the Benioff strain starts, have been considered. The average of the origin time and the average of the magnitude of these shocks have been calculated for each preshock sequence. The calculations of the mean preshock time, , and of the mean preshock magnitude, , were repeated by taking in all 45 cases $t_{e}$ equal to the origin time of the mainshock minus three years. It was found that the calculated values remained almost unchanged, which shows the robustness of estimations of and . 


\section{Results}

Accelerating preshock seismic strain in the critical region starts decreasing at certain time, $\mathrm{t}_{\mathrm{e}}$, before the mainshock. For this region we considered in the present paper the mean time, , and the mean magnitude, , of the accelerating preshocks that occurred from the start time, $\mathrm{t}_{\mathrm{s}}$, up to the time $\mathrm{t}_{\mathrm{e}}$. The values of and are listed in Table (1).

Figure (2) shows a plot of the logarithm of the time difference, , between the origin time of the mainshock, $t_{c}$, and the mean origin time, , of the accelerating preshocks against the logarithm of the Benioff strain rate, $\operatorname{logs}_{\mathrm{a}}$. The data are fitted, in the least squares' sense, by the relation:

Figure (3) shows a plot of the mainshock magnitude against the mean magnitude, , of accelerating preshocks. The data are fitted, in the least squares' sense, by the relation:

where $\sigma$, in both relations (2) and (3), is the standard deviation.

Relations (2) and (3) fit well a large sample of data and are of global validity because these data concern regions of a variety of seismotectonic regimes and of several levels of seismicity (with values of $\log _{\mathrm{a}}$ from 4.5 for west Mediterranean to 6.5 for Japan). These relations can be used as additional constraints for the estimation (prediction) of the origin time and magnitude of an ensuing mainshock by the D-AS or any other predicting model.

\section{Discussion}

In the D-AS model developed by Papazachos et al., (2006a) one of the constraints on which the estimation (prediction) of the origin time, $t_{c}$, of the ensuing mainshock is based, is a relation similar to relation (2). In that relation the start time, $\mathrm{t}_{\mathrm{sa}}$, of the accelerating preshock sequence is used instead of which is used in the present work. The data in this relation are more scattered $(\sigma=0.10)$ than the data used to derive relation (2) $(\sigma=0.07)$, although both procedures were applied in the same preshock sequences. In the beginning of an accelerating sequence the frequency of preshocks is very small and almost indistinguishable from the background seismicity. This has an effect on the accuracy of definition of $t_{\mathrm{sa}}$ which then affects the accuracy of estimation (prediction) of the origin time, $t_{c}$, of the mainshock. On the contrary, is based on the origin time of a large number of preshocks and for this reason is robust which results in more accurate estimation (prediction) of the origin time of the probably ensuing mainshock.

The mean magnitude, , of the three largest accelerating preshocks is also used by the D-AS model as a constraint for the estimation (prediction) of the mainshock magnitude (Papazachos et al., 2005, 2006a). Similarly, is based on a much larger sample of observations and for this reason its estimation is more reliable. This justifies the use of relation (3) as an additional constraint for the estimation (prediction) of the mainshock magnitude.

The results of the present work are based on the origin times and magnitudes of preshocks occurred up to the time $\mathrm{t}_{\mathrm{e}}$ (about three years before the occurrence of the mainshock). This puts 
a limit to the estimation of the mainshock origin time and magnitude by this procedure, because relations (2) and (3) cannot be applied until the time when the maximum value of the quality index is observed. The identification of that time suggests a continuous monitoring of the seismic activity of the area where a D-AS pattern is observed. As a result of this monitoring the initial estimation (prediction) of the parameters can be improved by the use of newly coming additional data. The results of the present work can contribute to such an improvement in the estimation of the origin time and magnitude of an ensuing mainshock.

Relations similar to (2) and (3) probably hold for decelerating preshocks. The available data, however, do not allow, at present, the definition of such relations for decelerating preshocks because these are much smaller than accelerating ones and for this reason strict completeness of data samples comprising small magnitudes is difficult to be achieved.

\section{Acknowledgements}

The author would like to thank B.C. Papazachos for his scientific support. Thanks are also due to Wessel and Smith (1995) for freely distributing the GMT software that was used to produce the first figure of the present study.

\section{References}

Ben-Zion, Y. and Lyakhovsky, V., 2002. Accelerated seismic release and related aspects of seismicity patterns on earthquake faults, Pure and Appl. Geoph. 159, 2385-2412.

Bowman, D.D., Quillon, G., Sammis, C.G., Sornette, A. and Sornette D., 1998. An observational test of the critical earthquake concept, J. Geophys. Res. 103, 24359-24372.

Bowman, D.D. and King G.C., 2001. Accelerating seismicity and stress accumulation before large earthquakes, Geophys. Res. Lett. 28, 4039-4042.

Brehm, D.J. and Braile L.W., 1999. Intermediate-term earthquake prediction using the modified time-to-failure method in southern California, Bull. Seism. Soc. Am. 89, 275-293.

Bufe, C.G. and Varnes D.J., 1993. Predictive modeling of seismic cycle of the Great San Francisco Bay Region, J. Geophys. Res. 98, 9871-9883.

Karakaisis, G.F., Savvaidis, A.S, and Papazachos, C.B., 2003. Time variation of parameters related to the accelerating preshock crustal deformation in the Aegean area, Pure Appl. Geophys. 160, 1479-1491.

Karakaisis, G.F., Scordilis, E.M., Papazachos, C.B. and Papazachos, B.C., 2006. A catalogue of earthquakes in California for the period 1901-2006, Publ. Geoph. Laboratory, University of Thessaloniki.

King, G.C., and Bowman D.D., 2003. The evolution of regional seismicity between large earthquakes, J. Geophys. Res. 108(B2), 2096, doi:10.1029/2001JB000783.

Knopoff, L., Levshina, T., Keilis-Borok, V.J. and Mattoni C., 1996. Increase long-range intermediate-magnitude earthquake activity prior to strong earthquakes in California, J. Geophys. Res. 101, 5779-5796.

Papaioannou, Ch.A., Scordilis, E.M., Papazachos, C.B., Karakaisis, G.F. and Papazachos, B.C., 2006. A catalogue of earthquakes in central and south America for the period 1900-2006, Publ. Geoph. Laboratory, University of Thessaloniki.

Papazachos, B.C., Scordilis, E.M., Papazachos, C.B. and Karakaisis, G.F., 2006b. A forward test of the precursory decelerating and accelerating seismicity model in California, J. Seismology 10, 213-224. 
Papazachos, B.C., Comninakis, P.E., Scordilis, E.M., Karakaisis, G.F. and Papazachos, C.B., 2006c. A catalogue of earthquakes in Mediterranean and surrounding area for the period 1901-2006, Publ. Geoph. Laboratory, University of Thessaloniki.

Papazachos, B.C., Karakaisis, G.F., Papazachos, C.B. and Scordilis, E.M., 2007. Evaluation of the Results for an Intermediate-Term Prediction of the 8 January $2006 M_{\mathrm{w}} 6.9$ Cythera Earthquake in the Southwestern Aegean, Bull. Seism. Soc. Am. 97, 347-352.

Papazachos, C.B., Karakaisis, G.F., Scordilis, E.M. and Papazachos B.C., 2005. Global observational properties of the critical earthquake model, Bull. Seism. Soc. Am. 95, 1841-1855.

Papazachos, C.B., Karakaisis, G.F., Scordilis, E.M. and Papazachos B.C., 2006a. New observational information on the precursory accelerating and decelerating strain energy release, Tectonophysics 423, 83-96.

Rundle, J.B., Turcotte, D.L., Shcherbakov, R., Klein, W. and Sammis, C., 2003. Statistical physics approach to understanding the multiscale dynamics of earthquake fault systems, Rev. Geophys. $41,5 / 1-5 / 30$.

Scordilis, E.M., 2005. Globally valid relations converting $\mathrm{M}_{\mathrm{s}}, \mathrm{m}_{\mathrm{b}}$ and $\mathrm{M}_{\mathrm{JMA}}$ to $\mathrm{M}_{\mathrm{w}}$, Meeting on earthquake monitoring and seismic hazard mitigation in Balkan countries. NATO ARW, Borovetz , Bulgaria, 11-17 September 2005, 158-161.

Scordilis, E.M., 2006. Empirical global relations converting $\mathrm{M}_{\mathrm{s}}$ and $\mathrm{m}_{\mathrm{b}}$ to moment magnitude, $J$. Seismology 10, 225-236.

Scordilis, E.M., Papazachos, C.B., Karakaisis, G.F. and Karakostas,V.G., 2004. Accelerating seismic crustal deformation before strong mainshocks in Adriatic and its importance for earthquake prediction, J. Seismology 8, 57-70.

Scordilis, E.M., Papazachos, C.B., Karakaisis, G.F. and Papazachos B.C., 2006. A catalogue of earthquakes in central Asia for the period 1901-2006, Publ. Geoph. Laboratory, University of Thessaloniki.

Sornette, D., and Sammis C.G., 1995. Complex critical exponents from renormalization group theory of earthquakes: implications for earthquake predictions, J. Phys. I. 5, 607-619.

Sykes, L.R. and Jaumé S., 1990. Seismic activity on neighboring faults as a long term precursor to large earthquakes in the San Francisco Bay area, Nature 348, 595-599.

Tocher, D., 1959. Seismic history of the San Francisco bay region, Calif. Div. Mines Spec. Rep. 57, 39-48.

Tzanis, A., Vallianatos, F. and Makropoulos K., 2000. Seismic and electrical precursors to the 171-1983, M=7 Kefallinia earthquake, Greece, signatures of a SOC system, Phys. Chem. Earth (a) $25,281-287$.

Varnes, D.J., 1989. Predicting earthquakes by analyzing accelerating precursory seismic activity, Pure Appl. Geophys. 130, 661-686.

Wessel, P. and Smith, W., 1995. New version of the Generic Mapping Tools, EOS 76-329. 